\title{
Tissue factor in tumor microenvironment: a systematic review
}

\author{
Xiao Han ${ }^{1}$, Bo Guo ${ }^{1}$, Yongsheng $\mathrm{Li}^{1,2^{*}}$ and Bo Zhu ${ }^{1,3^{*}}$
}

\begin{abstract}
The aberrant hemostasis is a common manifestation of cancer, and venous thromboembolism (VTE) is the second leading cause of cancer patients' mortality. Tissue factor (TF), comprising of a 47-kDa transmembrane protein that presents in subendothelial tissues and leukocytes and a soluble isoform, have distinct roles in the initiation of extrinsic coagulation cascade and thrombosis. Laboratory and clinical evidence showed the deviant expression of TF in several cancer systems and its tumor-promoting effects. TF contributes to myeloid cell recruitment in tumor stroma, thereby remodeling of tumor microenvironment. Additionally, the number of TF-positive-microparticles $\left(\mathrm{TF}^{+} \mathrm{MP}\right.$ ) from tumor origins correlates with the VTE rates in cancer patients. In this review, we summarize our current understanding of the TF regulation and roles in tumor progression and clinical complications.
\end{abstract}

Keywords: Tissue factor, Tumor microenvironment, Venous thromboembolism, Microparticles, Coagulation

\section{Introduction}

Tissue factor (TF), which consist of a 47-KDa-glycoprotein consisting of 263 amino acids (aa) (also named full-length TF (flTF) factor III, thromboplastin, or CD142) and an alternatively splice isoform, are encoded by $F 3$ gene. The $F 3$ gene locates on chromosome 1p22-p21 and contains 6 exons that produce a precursor protein with 294 amino acids. After posttranscriptional modification, the functional structure of precursor turns out to be a sausage shape membrane protein consisting of an extracellular domain (219 aa), a transmenbrane residue (23 aa) and a cytoplasmic part (21 aa) [1]. flTF is critical to initiate the extrinsic coagulation cascade in response to vascular endothelial disruption and enhances cell proliferation and migration [2].

The alternatively splice isoform of TF was identified in 2003. As this isoform is a splice variant, it was named alternatively spliced tissue factor (asTF). Compared to flTF, asTF is translated by a truncated mRNA transcript that lacks exon 5. Exon 5 of TF contains an exonic splicing enhancer (ESE) sequence motif, which can bind to

\footnotetext{
* Correspondence: yli@zeus.bwh.harvard.edu; b.davis.zhu@gmail.com ${ }^{1}$ Institute of Cancer, Xinqiao Hospital, Third Military Medical University, Chongqing 400037, PR China

${ }^{2}$ Harvard Institutes of Medicine, Department of Anesthesiology, Center for Experimental Therapeutics and Reperfusion Injury, Perioperative and Pain Medicine, Brigham and Women's Hospital and Harvard Medical School, Boston, MA 02115, USA

Full list of author information is available at the end of the article
}

the serine/arginine-rich proteins alternative splicing factor/pre-mRNA-splicing factor SF2 (ASF/SF2) and serinerich protein55 (SRp55), leading to the generation of flTF mRNA and translation of the flTF isoform protein [3]. The fusion of exon 4 and 6 creates a frameshift mutation and leads to a unique C-terminus, which enables asTF to be soluble and be secreted into extracellular fluids [4]. The coagulation activity of asTF has been debated since it was identified. Because asTF retains the conserved residues Lys165 and Lys166 which are important for substrate recognition during TF/factor VII activated (FVIIa) complex formation, some researchers believe that asTF maintains the factor $\mathrm{X}$ activated (FXa) generation ability and promote coagulation. Indeed, its presence in thrombi was demonstrated [4]. TNF- $\alpha$ and IL- 6 enhanced TFinduced coagulation in human umbilical venous endothelial cells (HUVECs) [5]. However, the location on a phospholipid membrane, a prerequisite for efficient macromolecular substrate binding, was abolished by the soluble $\mathrm{C}$-terminus of asTF, which may result in the disability of its procoagulant effect. Meanwhile, the experimental methods used in those studies did not exclude the possibility that the coagulant activity might be due to flTF indirectly, since it is extremely difficult to distinguish the precise role of two TF isoforms in coagulation in pro-coagulant assay [6]. Moreover, in FX activation assay, the cell lysate of asTF_FLAGtransfected HEK293 cells could not lead to FX activation, 
while flTF_FLAG-transfected HEK293 cells showed significant conversion of FX to FXa [7]. To date, no tissue and/or naturally occurring biological settings have been described that asTF is present without the full length isoform flTF [8] new approaches with higher sensitivity and specificity are needed for this scientific issue.

In 1865, Armand Trousseau first described thrombophlebitis (also known as Trousseau's syndrome) as a complication of pancreatic cancer. Since then, the idea that TF is involved in cancer development, including cell proliferation, survival, angiogenesis, epithelial-to-mesenchymal transition (EMT), and metastasis, has been gradually accepted [4,9-15]. In some malignant cancer systems, elevated TF expression can be detected in the serum as well as in tumor tissues [16-18]. In addition, tumor-derived TF-positive microparticles $\left(\mathrm{TF}^{+}-\mathrm{MPs}\right)$ are abundant in the plasma of patients with advanced diseases [19-21], which also highly correlates with venous thromboembolism (VTE) [22,23]. These findings indicate that targeting TF have potential significance for tumor diagnosis and therapy.

In this review, we shall overview the current understanding of the regulation and functions of TF in different stages of cancer progression. TF-related complications in tumor patients and TF-targeted therapy in clinical trials will also be discussed.

\section{Sources of TF and their regulation in cancer}

Ectopic expression of TF has been detected in several type of cancers, including cervical cancers [18], epithelial ovarian cancer (EOC) [24], breast cancer [25], brain tumors [26], pancreatic cancer [27], gastric cancer [28], prostate cancer [29], colorectal cancer (CRC) [30], lung cancer [31], melanoma [32], and several cancer cell lines, including human promyelocytic leukemia tumor cell lines HL-60, glioma cell line U343, gastric cell line KATOIII, SNU-5 and MKN-74, colon cancer line HCT116, epidermoid carcinoma cell line A431, melanoma cell line WM1341B and WM938A [4,33]. In addition, endothelial cells of tumor blood vessels, fibroblast and inflammatory cells also express TF [34,35]. Cervical tumors, pancreatic cancer and breast cancer specimens expressed asTF in both tumor cells and the stroma [12,36,37]. Two distinct forms of flTF, membrane-bound flTF [38] and $\mathrm{TF}^{+}$-MPs [39], are important for malignancy progression. Both tumor cells and monocytes are the main sources of $\mathrm{TF}^{+}$-MPs. Platelets and neutrophils also contribute to the production of $\mathrm{TF}^{+}$-MPs [19]. For the detail cell source of TF, see online GEO database (GSE3239).

Given the aberrant TF expression in tumor cells, oncogenic signaling pathways participate in TF regulation (Figure 1). Evidence from in vivo experiments and

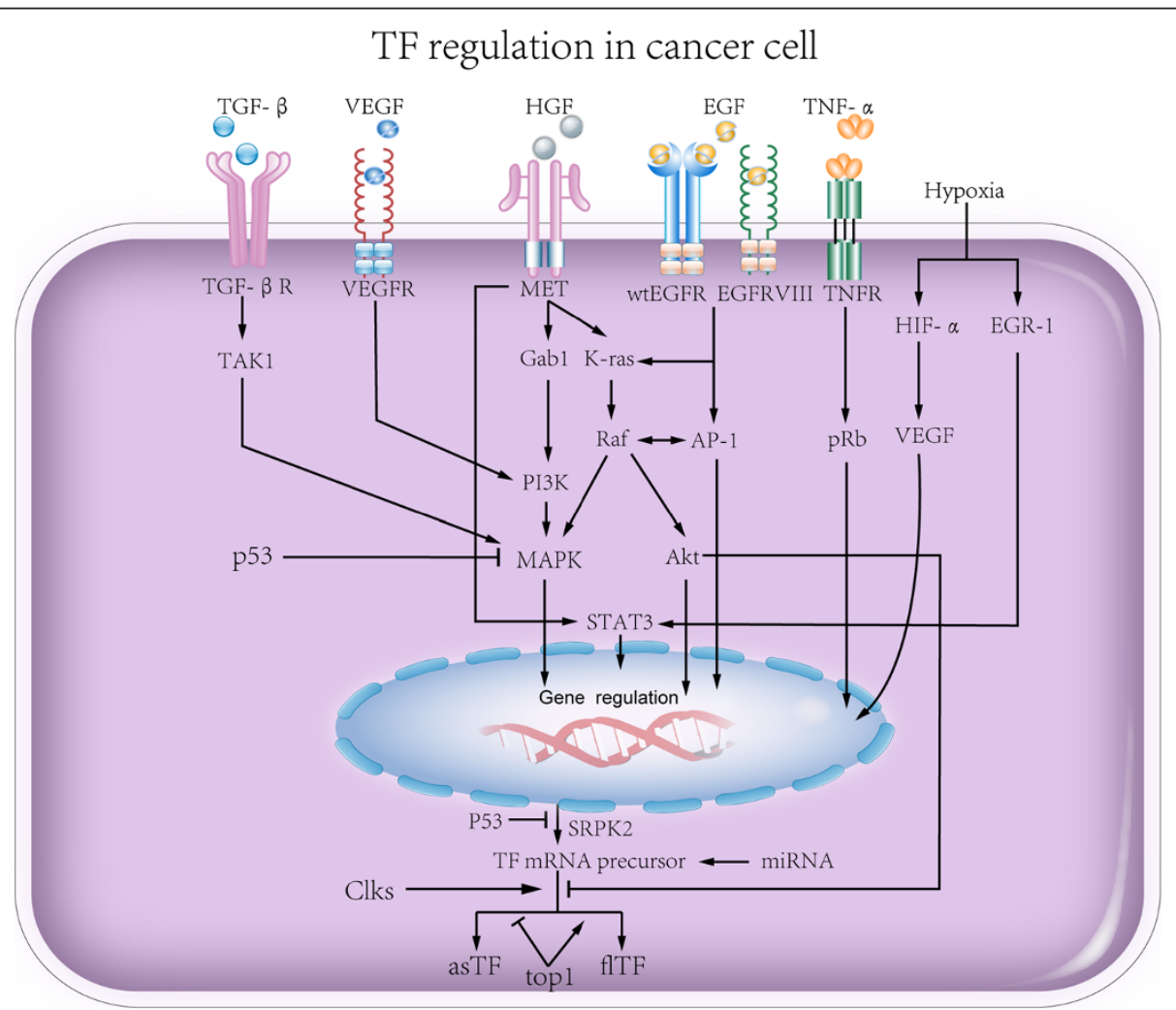

Figure 1 Signaling pathways involved in TF expression. TGF- $\beta$, VEGF, HGF, EGF, TNFa, and hypoxia challenge as well as p53 each regulates TF transcription and translation. 
clinical data revealed that the proto-oncogene K-ras and mutation of the tumor suppression gene p53, are primarily responsible for the upregulation of flTF. The loss function of p53 or activation of K-ras results in the activation of mitogen-activated protein kinase (MAPK)/ phosphoinositide-3 kinase (PI3K) signaling pathway and subsequent induction of flTF expression [40,41]. In squamous cell carcinoma and brain tumors, epidermal growth factor receptor (EGFR) and its mutant form EGFRvIII also regulate the expression of flTF, FVII, protease-activated receptor 1 (PAR1) and PAR2 [42]. Additionally, EGFR can activate TF transcription via activator protein-1 (AP-1), thus further increases TF expression [43]. AsTF expression is modulated by SF2/ASF and SRp75 through the PI3K/Akt pathway [44]. c-MET-Src family kinases are required for hepatocyte growth factor (HGF)/scatter factor induced TF expression in medulloblastoma cells. Mutation of c-MET leads to the antiapoptotic response and resistance to chemotherapy [45]. Retinoblastoma protein $(\mathrm{Rb})$, which can be induced by TNF- $\alpha$ [46], is an important oncogenic element leading to the aberrant expression patterns and proliferation of cancer cells [47]. flTF can be significantly upregulated in retinoblastoma cells expressing mutant $\mathrm{pRb}$, a member of $\mathrm{Rb}$ gene family [48]. In addition, TNF- $\alpha$, interferon-gamma (IFN- $\gamma$ ), early growth response gene-1 (EGR-1), hypoxiainducible factor 1 alpha (HIF-1 $\alpha$ ), and transforming growth factor-beta (TGF- $\beta$ ) upregulate flTF in cancer cells and endothelial cells [6,49-51]. TNF- $\alpha$ induces both TF isoform expression in HUVEC. Interestingly, this TNF- $\alpha$-induced TF expression can be reduced by CDC-2 like kinases (Clks) inhibitor [52], whereas DNA topoisomerase I inhibition upregulates asTF and reduces flTF expression [6]. Moreover, microRNAs also involved in TF posttranscriptional regulation $[53,54]$. Inhibition of miR-19a or miR-126 induces the expression of both TF isoforms, asTF and flTF, in endothelial cells under normal as well as under inflammatory conditions, thereby reduces the flTF-mediated pro-coagulant activity of these cells [53-55]. Moreover, miR-19b and miR-20a, for instance, play a role in flTF regulation in colon cancer and SLE [56,57]. In medulloblastoma, flTF expression is accompanied by miR-520 g silencing, and overexpression of miR-520 g suppresses flTF levels [58]. More details about the regulation of the TF isoform expression were reviewed by Leppert et al. [59].

Collectively, TF is universally expressed in tumor cells, immune cells and stromal cells. Its overexpression in tumors suggests a potential marker and therapeutic target for cancer. Understanding the roles of TF in cancer could potentially improve our knowledge of carcinogenesis.

\section{Functions of TF in tumor progression}

Downstream events of TF activation include thrombin generation, fibrin deposition, platelet activation, tumor- associated macrophage (TAM) recruitment, and metastasis via EMT [60]. Here, we mainly focus on TF functions in four aspects of cancer: sustaining proliferating signaling, resisting cell death, activating invasion and metastasis, avoiding immune destruction, and lethiferous clinical complications such as VTE (Figures 2 and 3).

\section{TF regulates tumor cell proliferation and apoptosis}

flTF and asTF promote tumor cell proliferation through different mechanisms (Figure 2) [12,61]. flTF/FVIIa complex can activate PAR2, leading to AP-1 phosphorylation, cell proliferation and migration in the colon cancer SW620 cell line [62]. Furthermore, activation of PAR2 by flTF induces protein kinase $\mathrm{C} \alpha(\mathrm{PKC} \alpha)$ phosphorylation and translocation from the cytoplasm to the perinuclear region, promotes ERK1/2 and NF- $\mathrm{KB}$ phosphorylation [61]. Breast cancer cell apoptosis can be suppressed by flTF via PI3K/Akt signaling pathway and reducing IL-8 and death-associated protein kinase 1 (DAPK1) [63]. The variant isoform asTF also promotes tumor growth in pancreatic and lung cancer setting $[31,64,65]$. Different from flTF, asTF enhances tumor cell proliferation through integrin signaling [12] which was also reviewed in detail by Leppert et al. in 2014 [59].

\section{TF promotes tumor angiogenesis and metastasis}

Blood vessels in tumor tissues are essential for tumor progression, and neovasculature is a prerequisite for bloodborne metastasis. In primary breast cancer cells, flTF/ FVIIa/PAR2 induces the production of pro-angiogenic factors and immune regulators [66]. Meanwhile, evidence from Hobbs et al. demonstrated that nude mice carrying asTF-overexpressing pancreatic ductal adenocarcinoma cells developed significantly larger tumors and increased angiogenesis than flTF-overexpressing cells [65]. asTF enhances pro-angiogenesis and pro-migration ability of cardiac cells via inducing angiogenesis- and migrationpromoting factors such as fibroblast growth factor 2 (FGF2), cysteine-rich 61 (Cyr61) and vascular endothelial growth factor (VEGF). Meanwhile, monocytic THP-1 cells exhibit enhanced migration after treated with the supernatant of asTF-overexpressing mouse cardiomyocytic HL1 cell [11]. Hypoxia exposure induces asTF expression in A549 cells through alternative splicing factors Clk1 and Clk4. The elevated asTF promotes the tube formation of A549 cells by increasing Cyr61, CC chemokine ligand (CCL2) and VEGF [31]. Different from flTF-PAR interaction, asTF possesses its potent pro-angiogenic properties through interacting with integrin $\beta 1$ and $\beta 3$ in endothelial cell, eliciting focal adhesion kinase (FAK), p42/p44, p38 MAPK and Akt phosphorylation [36]. $6 \mathrm{~B} 4$, an antibody which disrupts the TF-integrin interaction, can efficiently inhibit the pro-angiogenic function of asTF [67]. 


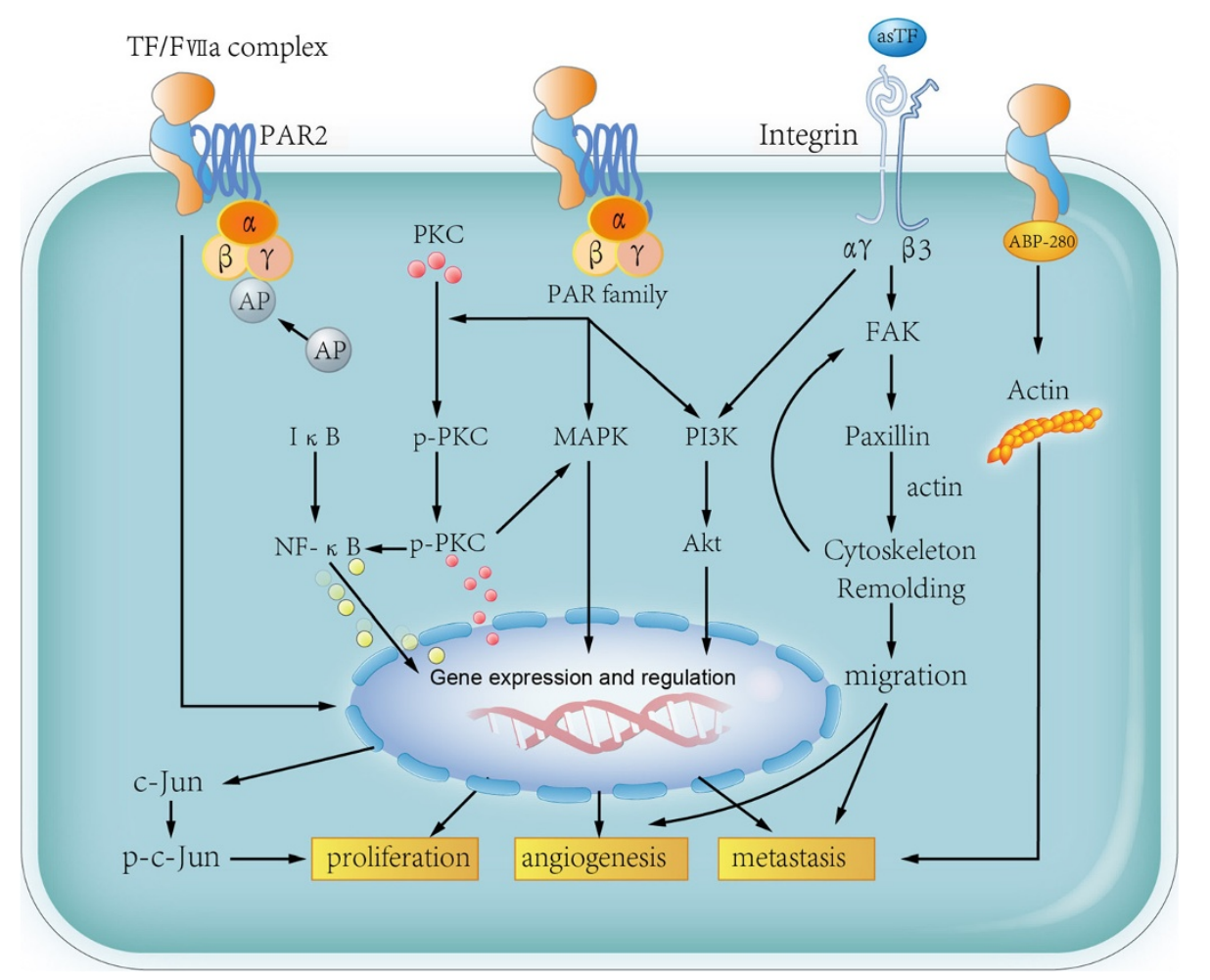

Figure 2 Function of TF in cancer progression. fITF forms TF/FVIla complex and subsequently induce PAR signaling. PKC is phosphorylated by activated PAR complex, which leads to p-PKC translocation. PAR can also induce MAPK and PI3K activation, both of which trigger pro-tumor effects, such as proliferation, angiogenesis and metastasis. Binding to activator protein (AP) can also induce c-Jun upregulation and in turn promote tumor progression. Moreover, fITF binding to ABP-280 leads to actin modulation, resulting in tumor cells metastasis. asTF binds to integrin receptor and enhance the ability of migration, in turn leading to tumor cell angiogenesis and migration.

In addition to the pro-angiogenic effects in cancer, $\mathrm{TF}$ also regulate cytoskeleton remodeling, which enhances tumor cell migration and subsequently promotes metastasis. flTF stimulates tumor cell migration through cytoplasmic domain by activating p38 in a Rac 1 dependent manner [68]. Specific interaction between the flTF cytoplasmic domain with actin-binding protein 280 (ABP280) also contributes to tumor cell metastasis and vascular remodeling [69]. However, flTF exhibits its pro-metastatic characteristics mainly by initiating the pro-coagulant cascade, including thrombin formation, fibrin generation and platelet activation [70,71]. The fibrin (ogen)-platelet clot formation is essential for generating a shield around tumor cells to facilitate the spread of tumor cells and the escape of newly formed micrometastasis from natural killer (NK) cellmediated cytolysis [72,73]. TFPI, an inhibitor of TF, can significantly reduce the metastasis of B16F10 murine melanoma cells [74]. The TF-induced coagulation can promote TAMs recruitment and the establishment of the pro-metastatic niche [75].

Cancer stem cells (CSC), which express CD133 [76], CD44, ATP-binding cassette sub-family G member 2 (ABCG2) and Aldehyde dehydrogenases (ALDH) [77], are a subpopulation of tumor cells that display self- renewal and the ability to give rise to heterogeneous lineages of cancer cells. These heterogeneous cells are responsible for tumor initiation, angiogenesis, and metastasis. Results from our lab revealed that $\mathrm{CD} 133^{+}$ ovarian cancer stem cells remarkably over express flTF compared with $\mathrm{CD}_{133^{-}}$cancer cells [78]. Moreover, evidence from Chloe C. Milsom and her colleagues demonstrated that the TF-blocking antibody (CNTO 859) delays A431 cell initiation and metastasis through blocking EMT [79]. The functions of TF in angiogenesis and metastasis as well as the location of CSCs in the perivascular niche suggest that the interfering with CSCs by targeting TF would be of interest and worth for further research.

Hence, the expression of TF can effectively enhance angiogenesis and coagulation-associated metastasis via either the interaction of the cytoplasmic domain with the PAR family, or through the integrin signaling pathway (Figures 2 and 3 ).

\section{TF modulate immune responses within the tumor microenvironment}

Cytotoxic T lymphocytes and NK cells are the major effector cells mediating anti-tumor immunity. However, 


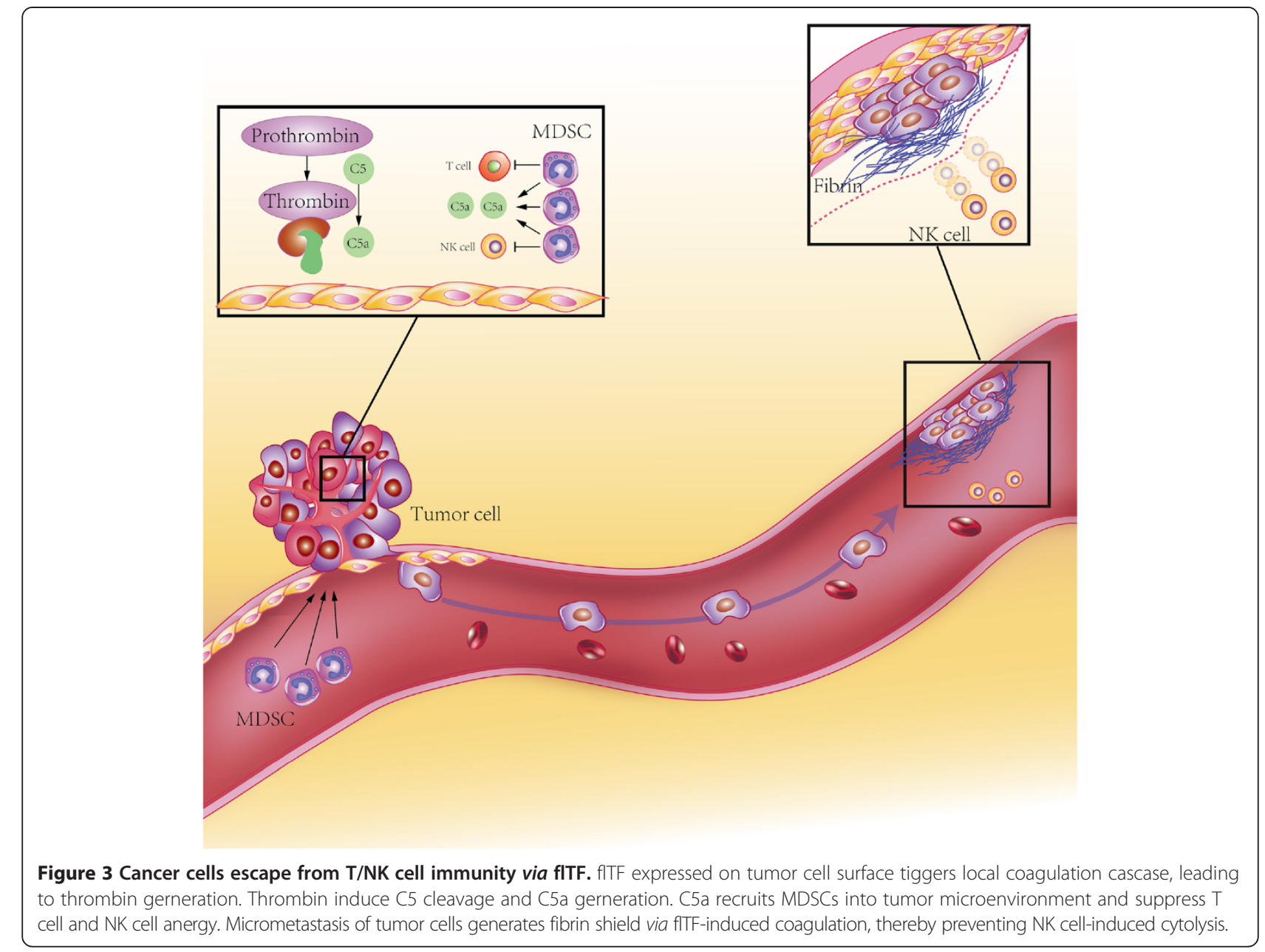

anti-tumor immunity is abrogated primarily due to the dysfunction of cytotoxic T lymphocytes and NK cells and the accumulation of myeloid-derived suppressor cells (MDSCs) in the tumor microenvironment [80]. As mentioned above, flTF is responsible for local thrombin generation and fibrin deposition. Once thrombin is generated, it can directly cleaves complement component C5 to produce C5a and C5b [81]. C5a, also known as anaphylatoxin, has a pro-tumor effect via recruiting MDSCs to the tumor microenvironment, resulting in an immunosuppressive milieu [82] (Figure 3). Meanwhile, TF-mediated thrombosis within the tumor microenvironment may cause local ischemia and hypoxia, leading to the local inflammatory response and tumor tissue necrosis. The TF-induced hypoxia could in turn upregulate flTF, Clk1 and Clk4, resulting in asTF production [31]. This potential positive feedback loop may contribute to tumor cell proliferation and angiogenesis, as well as increase MDSC infiltration within the tumor microenvironment. TF-triggered tumor cell-clot formation induces vascular cell adhesion molecule-1 (VCAM-1) expression and the recruitment of myeloid cells, and promotes tumor invasion and metastasis [83]. Taken together, TF assists tumor cells to metastasis and escape from the host immune system via modulating the tumor microenvironment.

\section{TF expression correlates with increased VTE}

Since VTE, particularly deep venous thrombosis of the lower extremities and pulmonary embolism, comprises the second leading cause of death in cancer patients [84], efficient anticoagulation therapies are of profound clinical importance. Clinical studies indicate that administration of low molecular weight heparins (LMWH) in cancer patients significantly improves survival [85-87].

The phosphatidylserine (PS) acts synergistically with flTF to amplify its role as a coagulation initiator $[21,88]$. Both flTF and PS in systemic circulation assemble on the surface of MPs from tumors, resulting in the formation of the coagulation complex. Therefore, circulating tumor cell-derived $\mathrm{TF}^{+}$-MPs may trigger venous thrombosis formation in the absence of vessel injury. $\mathrm{TF}^{+}$-MPs in the systemic circulation of patients with advanced colorectal cancer increased the risk of VTE by two fold 
when compared with healthy controls [89]. Another study showed that cancer patients suffering from VTE had a higher level of $\mathrm{TF}^{+}$-MPs compared with those without VTE [90]. In addition to the plasma antigen level, an increase of $\mathrm{TF}^{+}$-MPs activity in cancer patients with VTE was reported by several groups. Tessellar et al. observed a higher level of $\mathrm{TF}^{+}$-MPs activity in acute VTE patients than in patients without VTE [91,92]. Owens and Mackman found elevated MP-TF activity in 9 of 11 patients [19]. Similarly, Zwicher et al. reported a 7fold increased risk of thrombosis in VTE-free patients with elevated $\mathrm{TF}^{+}$-MP levels than in VTE-free plus $\mathrm{TF}^{+}$-MPs negative patients [93]. The association between mortality and the level of $\mathrm{TF}^{+}$-MPs was also demonstrated. Tesselaar and Bharthuar individually reported that in breast cancer and pancreaticobiliary cancer, patients with VTE, who presented higher level of MP-TF activity, had a lower survival rate than patients with lower levels of MP-TF activity [23,91]. These studies indicate that $\mathrm{TF}^{+}$-MP amount and MP-TF activity may have prognostic values in cancer patients.

\section{Conclusion and prospective}

In conclusion, the traditional extrinsic coagulation pathway initiator flTF and its isoform actively participate in malignant disease progression. The signaling pathways associated with TF are critical for tumor initiation, growth, angiogenesis and metastasis and clinical complications such as VTE. Targeting flTF and anticoagulation therapies have already been used for several types of cancer [26]. Understanding the precise regulatory mechanisms of flTF as well as its soluble isoform asTF in tumor progression could be of potential interest for improving the theory of tumor immunoediting and developing individual therapeutic strategies for cancer.

\footnotetext{
Abbreviations

ABP-280: Actin-binding protein 280; ABCG2: ATP-binding cassette sub-family G member 2; ALDH: Aldehyde dehydrogenase; AP-1: Activator protein-1; APC: Activated protein C; APL: Acute promyelocytic leukemia;

ASF/SF2: Alternative splicing factor/pre-mRNA-splicing factor SF2; asTF: Alternatively spliced tissue factor; ATRA: All-trans retinoic acid; CCL2: CC chemokine ligand; Clk: CDC-2 like kinases; CRC: Colorectal cancer; CSCs: Cancer stem cells; Cyr61: Cysteine-rich 61; EGFR: Epidermal growth factor receptor; EGR-1: Early growth response gene-1; EMT: Epithelial-tomesenchymal transition; EOC: Epithelial ovarian cancer; ESE: Exonic splicing enhancer; FAK: Focal adhesion kinase; FGF: Fibroblast growth factor; fITF: Full-length tissue factor; HGF: Hepatocyte growth factor; JNK: c-Jun amino-terminal kinase; LMWH: Low molecular weight heparins; MAC: Membrane attack complex; MAPK: Mitogen-activated protein kinase; MDSCs: Myeloid-derived suppressor cells; MMP-1: Matrix

metalloproteinase-1; MPM: Malignant pleural mesothelioma; NSCLC: Non-small cell lung cancer; OCSC: Ovarian cancer stem cells; PAK-1: p21-activated kinase 1; PAR: Protease-activated receptor; PDGF: Platelet-derived growth factor; PI3K: Phosphoinositide-3 kinase; PKCa: Protein kinase Ca: PS: Phosphatidylserine; RAS: Renin-angiotensin system; TAMs: Tumor associated macrophages; TF: Tissue factor; TF $^{+}$-MPs: Tissue factor-positive microparticles; TFPI: Tissue factor pathway inhibitor; TICs: Tumor-initiating cells; TM: Thrombinmodulin; VCAM-1: Vascular cell adhesion molecule-1; VEGF: Vascular endothelial growth factor; VTE: Venous thromboembolism
}

\section{Competing interests}

The authors declare that they have no competing interests.

\section{Authors' contributions}

$\mathrm{XH}, \mathrm{YL}$ and $\mathrm{BZ}$ drafted the manuscript and figures; $\mathrm{YL}, \mathrm{BG}$ and $\mathrm{BZ}$ contributed to editing of the manuscript. All authors have read and approved the final manuscript.

\section{Acknowledgements}

This work is supported by National Nature Science Foundation of China (No. 81372271, No. 81071772, and No. 81222031) and by National Key Basic Research Program of China (973 program, No. 2010 CB529404 and No. 2012CB526603).

\section{Author details}

${ }^{1}$ Institute of Cancer, Xinqiao Hospital, Third Military Medical University, Chongqing 400037, PR China. ${ }^{2}$ Harvard Institutes of Medicine, Department of Anesthesiology, Center for Experimental Therapeutics and Reperfusion Injury, Perioperative and Pain Medicine, Brigham and Women's Hospital and Harvard Medical School, Boston, MA 02115, USA. ${ }^{3}$ Biomedical Analysis Center, Third Military Medical University, Chongqing 400038, China.

Received: 18 June 2014 Accepted: 9 July 2014

Published: 1 August 2014

\section{References}

1. Spicer EK, Horton R, Bloem L, Bach R, Williams KR, Guha A, Kraus J, Lin TC, Nemerson $Y$, Konigsberg WH: Isolation of CDNA clones coding for human tissue factor: primary structure of the protein and CDNA. Proc Natl Acad Sci U S A 1987, 84:5148-5152.

2. Versteeg HH, Peppelenbosch MP, Spek CA: The pleiotropic effects of tissue factor: a possible role for factor Vlla-induced intracellular signalling? Thromb Haemost 2001, 86:1353-1359.

3. Tardos JG, Eisenreich A, Deikus G, Bechhofer DH, Chandradas S, Zafar U, Rauch U, Bogdanov VY: SR proteins ASF/SF2 and SRp55 participate in tissue factor biosynthesis in human monocytic cells. J Thromb Haemost 2008, 6:877-884.

4. Bogdanov VY, Balasubramanian V, Hathcock J, Vele O, Lieb M, Nemerson Y: Alternatively spliced human tissue factor: a circulating, soluble, thrombogenic protein. Nat Med 2003, 9:458-462.

5. Szotowski B, Antoniak S, Poller W, Schultheiss HP, Rauch U: Procoagulant soluble tissue factor is released from endothelial cells in response to inflammatory cytokines. Circ Res 2005, 96:1233-1239.

6. Eisenreich A, Bogdanov VY, Zakrzewicz A, Pries A, Antoniak S, Poller W, Schultheiss HP, Rauch U: Cdc2-like kinases and DNA topoisomerase I regulate alternative splicing of tissue factor in human endothelial cells. Circ Res 2009, 104:589-599.

7. Censarek P, Bobbe A, Grandoch M, Schror K, Weber AA: Alternatively spliced human tissue factor (asHTF) is not pro-coagulant. Thromb Haemost 2007, 97:11-14.

8. Srinivasan R, Bogdanov VY: Alternatively spliced tissue factor: discovery, insights, clinical implications. Front Biosci 2011, 16:3061-3071.

9. Bick RL: Cancer-associated thrombosis. N Engl J Med 2003, 349:109-111.

10. Yu YJ, Li YM, Hou XD, Guo C, Cao N, Jiao ZY: Effect of tissue factor on invasion inhibition and apoptosis inducing effect of oxaliplatin in human gastric cancer cell. Asian Pac J Cancer Prev 2012, 13:1845-1849.

11. Eisenreich A, Boltzen U, Malz R, Schultheiss HP, Rauch U: Overexpression of alternatively spliced tissue factor induces the pro-angiogenic properties of murine cardiomyocytic HL-1 cells. Circ J 2011, 75:1235-1242.

12. Kocaturk B, Van den Berg YW, Tieken C, Mieog JS, de Kruijf EM, Engels CC, van der Ent MA, Kuppen PJ, Van de Velde CJ, Ruf W, Reitsma PH, Osanto S, Liefers GJ, Bogdanov VY, Versteeg HH: Alternatively spliced tissue factor promotes breast cancer growth in a beta1 integrin-dependent manner. Proc Natl Acad Sci U S A 2013, 110:11517-11522.

13. Liu Y, Jiang P, Capkova K, Xue D, Ye L, Sinha SC, Mackman N, Janda KD, Liu C: Tissue factor-activated coagulation cascade in the tumor microenvironment is critical for tumor progression and an effective target for therapy. Cancer Res 2011, 71:6492-6502.

14. Saito Y, Hashimoto Y, Kuroda J, Yasunaga M, Koga Y, Takahashi A, Matsumura $Y$ : The inhibition of pancreatic cancer invasion-metastasis 
cascade in both cellular signal and blood coagulation cascade of tissue factor by its neutralisation antibody. Eur J Cancer 2011, 47:2230-2239.

15. Schaffner $F$, Yokota $N$, Ruf W: Tissue factor proangiogenic signaling in cancer progression. Thromb Res 2012, 129(Suppl 1):S127-S131.

16. Welsh J, Smith JD, Yates KR, Greenman J, Maraveyas A, Madden LA: Tissue factor expression determines tumour cell coagulation kinetics. Int I Lab Hematol 2012, 34:396-402.

17. Hong H, Zhang Y, Nayak TR, Engle JW, Wong HC, Liu B, Barnhart TE, Cai W: Immuno-PET of tissue factor in pancreatic cancer. J Nucl Med 2012, 53:1748-1754

18. Cocco E, Varughese J, Buza N, Bellone S, Glasgow M, Bellone M, Todeschini P, Carrara L, Silasi DA, Azodi M, Schwartz PE, Rutherford TJ, Pecorelli S, Lockwood CJ, Santin AD: Expression of tissue factor in adenocarcinoma and squamous cell carcinoma of the uterine cervix: implications for immunotherapy with hl-con1, a factor VII-IgGFc chimeric protein targeting tissue factor. BMC Cancer 2011, 11:263.

19. Owens AP 3rd, Mackman N: Microparticles in hemostasis and thrombosis. Circ Res 2011, 108:1284-1297.

20. Rak J: Microparticles in cancer. Semin Thromb Hemost 2010, 36:888-906

21. Castellana D, Toti F, Freyssinet JM: Membrane microvesicles: macromessengers in cancer disease and progression. Thromb Res 2010, 125(Suppl 2):S84-S88.

22. Pabinger I, Thaler J, Ay C: Biomarkers for prediction of venous thromboembolism in cancer. Blood 2013, 122:2011-2018.

23. Bharthuar A, Khorana AA, Hutson A, Wang JG, Key NS, Mackman N, lyer RV: Circulating microparticle tissue factor, thromboembolism and survival in pancreaticobiliary cancers. Thromb Res 2013, 132:180-184.

24. Ma Z, Zhang T, Wang R, Cheng Z, Xu H, Li W, Wang Y, Wang X: Tissue factor-factor VIla complex induces epithelial ovarian cancer cell invasion and metastasis through a monocytes-dependent mechanism. Int J Gynecol Cancer 2011, 21:616-624.

25. Cole M, Bromberg M: Tissue factor as a novel target for treatment of breast cancer. Oncologist 2013, 18:14-18.

26. Perry JR: Thromboembolic disease in patients with high-grade glioma. Neuro Oncol 2012, 14(Suppl 4):iv73-iv80.

27. Thaler J, Ay C, Mackman N, Metz-Schimmerl S, Stift J, Kaider A, Mullauer L, Gnant M, Scheithauer W, Pabinger I: Microparticle-associated tissue factor activity in patients with pancreatic cancer: correlation with clinicopathological features. Eur J Clin Invest 2013, 43:277-285.

28. Yamashita H, Kitayama J, Ishikawa M, Nagawa $\mathrm{H}$ : Tissue factor expression is a clinical indicator of lymphatic metastasis and poor prognosis in gastric cancer with intestinal phenotype. J Surg Oncol 2007, 95:324-331.

29. Lwaleed BA, Lam L, Lasebai M, Cooper AJ: Expression of tissue factor and tissue factor pathway inhibitor in microparticles and subcellular fractions of normal and malignant prostate cell lines. Blood Coagul Fibrinolysis 2013, 24:339-343.

30. Li H, Tian ML, Yu G, Liu YC, Wang X, Zhang J, Ji SQ, Zhu J, Wan YL, Tang JQ: Hyperthermia synergizes with tissue factor knockdown to suppress the growth and hepatic metastasis of colorectal cancer in orthotopic tumor model. J Surg Oncol 2012, 106:689-695.

31. Eisenreich A, Zakrzewicz A, Huber K, Thierbach H, Pepke W, Goldin-Lang P, Schultheiss HP, Pries A, Rauch U: Regulation of pro-angiogenic tissue factor expression in hypoxia-induced human lung cancer cells. Oncol Rep 2013, 30:462-470.

32. Zhao Y, Zhang D, Wang S, Tao L, Wang A, Chen W, Zhu Z, Zheng S, Gao X Lu Y: Holothurian glycosaminoglycan inhibits metastasis and thrombosis via targeting of nuclear factor-kappaB/tissue factor/Factor Xa pathway in melanoma B16F10 cells. PLoS One 2013, 8:e56557.

33. Yu JL, Rak JW: Shedding of tissue factor (TF)-containing microparticles rather than alternatively spliced TF is the main source of TF activity released from human cancer cells. J Thromb Haemost 2004, 2:2065-2067.

34. Contrino J, Hair G, Kreutzer DL, Rickles FR: In situ detection of tissue factor in vascular endothelial cells: correlation with the malignant phenotype of human breast disease. Nat Med 1996, 2:209-215.

35. Vrana JA, Stang MT, Grande JP, Getz MJ: Expression of tissue factor in tumor stroma correlates with progression to invasive human breast cancer: paracrine regulation by carcinoma cell-derived members of the transforming growth factor beta family. Cancer Res 1996, 56:5063-5070.

36. van den Berg YW, van den Hengel LG, Myers HR, Ayachi O, Jordanova E, Ruf W, Spek CA, Reitsma PH, Bogdanov VY, Versteeg HH: Alternatively spliced tissue factor induces angiogenesis through integrin ligation. Proc Natl Acad Sci U S A 2009, 106:19497-19502.

37. Godby RC, Van Den Berg YW, Srinivasan R, Sturm R, Hui DY, Konieczny SF, Aronow BJ, Ozhegov E, Ruf W, Versteeg HH, Bogdanov VY:

Nonproteolytic properties of murine alternatively spliced tissue factor: implications for integrin-mediated signaling in murine models. Mol Med 2012, 18:771-779.

38. Rao LV, Pendurthi UR: Regulation of tissue factor coagulant activity on cell surfaces. J Thromb Haemost 2012, 10:2242-2253.

39. Rautou PE, Mackman N: Microvesicles as risk markers for venous thrombosis. Expert Rev Hematol 2013, 6:91-101.

40. Rao B, Gao Y, Huang J, Gao X, Fu X, Huang M, Yao J, Wang J, Li W, Zhang J, Liu H, Wang L: Mutations of $\mathrm{p} 53$ and K-ras correlate TF expression in human colorectal carcinomas: TF downregulation as a marker of poor prognosis. Int J Colorectal Dis 2011, 26:593-601.

41. Yu JL, May L, Lhotak V, Shahrzad S, Shirasawa S, Weitz Jl, Coomber BL, Mackman N, Rak JW: Oncogenic events regulate tissue factor expression in colorectal cancer cells: implications for tumor progression and angiogenesis. Blood 2005, 105:1734-1741.

42. Magnus N, Garnier D, Rak J: Oncogenic epidermal growth factor receptor up-regulates multiple elements of the tissue factor signaling pathway in human glioma cells. Blood 2010, 116:815-818.

43. Rong Y, Belozerov VE, Tucker-Burden C, Chen G, Durden DL, Olson JJ, Van Meir EG, Mackman N, Brat DJ: Epidermal growth factor receptor and PTEN modulate tissue factor expression in glioblastoma through JunD/activator protein-1 transcriptional activity. Cancer Res 2009, 69:2540-2549.

44. Eisenreich A, Malz R, Pepke W, Ayral Y, Poller W, Schultheiss HP, Rauch U: Role of the phosphatidylinositol 3-kinase/protein kinase B pathway in regulating alternative splicing of tissue factor mRNA in human endothelial cells. Circ J 2009, 73:1746-1752.

45. Provencal M, Labbe D, Veitch R, Boivin D, Rivard GE, Sartelet $H$, Robitaille $Y$, Gingras D, Beliveau R: c-Met activation in medulloblastoma induces tissue factor expression and activity: effects on cell migration. Carcinogenesis 2009, 30:1089-1096

46. Vieira KB, Goldstein DJ, Villa LL: Tumor necrosis factor alpha interferes with the cell cycle of normal and papillomavirus-immortalized human keratinocytes. Cancer Res 1996, 56:2452-2457.

47. Vogelstein B, Kinzler KW: Cancer genes and the pathways they control. Nat Med 2004, 10:789-799.

48. Lee BJ, Kim JH, Woo SH, Kim JH, Kim DH, Yu YS: Tissue factor is involved in retinoblastoma cell proliferation via both the Akt and extracellular signal-regulated kinase pathways. Oncol Rep 2011, 26:665-670.

49. Sun L, Liu Y, Lin S, Shang J, Liu J, Li J, Yuan S, Zhang L: Early growth response gene-1 and hypoxia-inducible factor-1alpha affect tumor metastasis via regulation of tissue factor. Acta Oncol 2013, 52:842-851.

50. Bastarache JA, Sebag SC, Grove BS, Ware LB: Interferon-gamma and tumor necrosis factor-alpha act synergistically to up-regulate tissue factor in alveolar epithelial cells. Exp Lung Res 2011, 37:509-517.

51. Wygrecka M, Zakrzewicz D, Taborski B, Didiasova M, Kwapiszewska G, Preissner KT, Markart P: TGF-beta1 induces tissue factor expression in human lung fibroblasts in a PI3K/JNK/Akt-dependent and AP-1-dependent manner. Am J Respir Cell Mol Biol 2012, 47:614-627.

52. Fedorov O, Huber K, Eisenreich A, Filippakopoulos $P$, King O, Bullock AN, Szklarczyk D, Jensen LJ, Fabbro D, Trappe J, Rauch U, Bracher F, Knapp S: Specific CLK inhibitors from a novel chemotype for regulation of alternative splicing. Chem Biol 2011, 18:67-76.

53. Eisenreich $A$ : Regulation of vascular function on posttranscriptional level. Thrombosis 2013, 2013:948765.

54. Eisenreich $A$, Leppert $U$ : The impact of microRNAs on the regulation of tissue factor biology. Trends Cardiovasc Med 2014, 24:128-132.

55. A E, Rauch U: Regulation of the tissue factor isoform expression and thrombogenicity of HMEC-1 by miR-126 and miR-19a. Cell Biol: Res Ther 2013, 2:1. doi:10.4172/2324-9293.1000101.

56. Yu G, Li H, Wang X, Wu T, Zhu J, Huang S, Wan Y, Tang J: MicroRNA-19a targets tissue factor to inhibit colon cancer cells migration and invasion. Mol Cell Biochem 2013, 380:239-247.

57. Teruel R, Perez-Sanchez C, Corral J, Herranz MT, Perez-Andreu V, Saiz E, Garcia-Barbera N, Martinez-Martinez I, Roldan V, Vicente V, Lopez-Pedrera C, Martinez $C$ : Identification of miRNAs as potential modulators of tissue factor expression in patients with systemic lupus erythematosus and antiphospholipid syndrome. J Thromb Haemost 2011, 9:1985-1992. 
58. Garnier D, Magnus N, D'Asti E, Hashemi M, Meehan B, Milsom C, Rak J: Genetic pathways linking hemostasis and cancer. Thromb Res 2012, 129(Suppl 1):S22-S29.

59. Leppert $U$, Eisenreich $A$ : The role of tissue factor isoforms in cancer biology. Int J Cancer 2014, doi:10.1002/ijc.28959.

60. van den Berg YW, Osanto S, Reitsma PH, Versteeg HH: The relationship between tissue factor and cancer progression: insights from bench and bedside. Blood 2012, 119:924-932.

61. Wu B, Zhou H, Hu L, Mu Y, Wu Y: Involvement of PKCalpha activation in TF/VIla/PAR2-induced proliferation, migration, and survival of colon cancer cell SW620. Tumour Biol 2013, 34:837-846.

62. Hu L, Xia L, Zhou H, Wu B, Mu Y, Wu Y, Yan J: TF/FVlla/PAR2 promotes cell proliferation and migration via PKCalpha and ERK-dependent c-Jun/AP-1 pathway in colon cancer cell line SW620. Tumour Biol 2013, 34:2573-2581.

63. Aberg M, Johnell M, Wickstrom M, Siegbahn A: Tissue Factor/FVlla prevents the extrinsic pathway of apoptosis by regulation of the tumor suppressor Death-Associated Protein Kinase 1 (DAPK1). Thromb Res 2011, 127:141-148.

64. Signaevsky M, Hobbs J, Doll J, Liu N, Soff GA: Role of alternatively spliced tissue factor in pancreatic cancer growth and angiogenesis. Semin Thromb Hemost 2008, 34:161-169.

65. Hobbs JE, Zakarija A, Cundiff DL, Doll JA, Hymen E, Cornwell M, Crawford SE, Liu N, Signaevsky M, Soff GA: Alternatively spliced human tissue factor promotes tumor growth and angiogenesis in a pancreatic cancer tumor model. Thromb Res 2007, 120(Suppl 2):S13-S21.

66. Maeda S, Maeda S, Ohno K, Kaji N, Hori M, Fujino Y, Tsujimoto H: Protease-activated receptor-2 induces proinflammatory cytokine and chemokine gene expression in canine keratinocytes. Vet Immunol Immunopathol 2013, 153:17-25.

67. Dorfleutner A, Hintermann E, Tarui T, Takada Y, Ruf W: Cross-talk of integrin alpha3beta1 and tissue factor in cell migration. Mol Biol Cell 2004, 15:4416-4425.

68. Ott I, Weigand B, Michl R, Seitz I, Sabbari-Erfani N, Neumann FJ, Schomig A Tissue factor cytoplasmic domain stimulates migration by activation of the GTPase Rac1 and the mitogen-activated protein kinase p38. Circulation 2005, 111:349-355.

69. Muller M, Albrecht S, Golfert F, Hofer A, Funk RH, Magdolen V, Flossel C, Luther T: Localization of tissue factor in actin-filament-rich membrane areas of epithelial cells. Exp Cell Res 1999, 248:136-147.

70. Palumbo JS: Mechanisms linking tumor cell-associated procoagulant function to tumor dissemination. Semin Thromb Hemost 2008, 34:154-160.

71. Ruf W, Mueller BM: Thrombin generation and the pathogenesis of cancer. Semin Thromb Hemost 2006, 32(Suppl 1):61-68.

72. Degen JL, Palumbo JS: Hemostatic factors, innate immunity and malignancy. Thromb Res 2012, 129(Suppl 1):S1-S5.

73. Palumbo JS, Barney KA, Blevins EA, Shaw MA, Mishra A, Flick MJ, Kombrinck KW, Talmage KE, Souri M, Ichinose A, Degen JL: Factor XIII transglutaminase supports hematogenous tumor cell metastasis through a mechanism dependent on natural killer cell function. J Thromb Haemost 2008, 6:812-819.

74. Amirkhosravi A, Meyer T, Chang JY, Amaya M, Siddiqui F, Desai $H$, Francis JL: Tissue factor pathway inhibitor reduces experimental lung metastasis of B16 melanoma. Thromb Haemost 2002, 87:930-936.

75. Gil-Bernabe AM, Ferjancic S, Tlalka M, Zhao L, Allen PD, Im JH, Watson K, Hill SA, Amirkhosravi A, Francis JL, Pollard JW, Ruf W, Muschel RJ: Recruitment of monocytes/macrophages by tissue factor-mediated coagulation is essential for metastatic cell survival and premetastatic niche establishment in mice. Blood 2012, 119:3164-3175.

76. Ma S: Biology and clinical implications of CD133(+) liver cancer stem cells. Exp Cell Res 2013, 319:126-132.

77. Liu S, Ginestier C, Ou SJ, Clouthier SG, Patel SH, Monville F, Korkaya H, Heath A, Dutcher J, Kleer CG, Jung Y, Dontu G, Taichman R, Wicha MS: Breast cancer stem cells are regulated by mesenchymal stem cells through cytokine networks. Cancer Res 2011, 71:614-624.

78. Long H, Xie R, Xiang T, Zhao Z, Lin S, Liang Z, Chen Z, Zhu B: Autocrine CCL5 signaling promotes invasion and migration of CD133+ ovarian cancer stem-like cells via NF-kappaB-mediated MMP-9 upregulation. Stem Cells 2012, 30:2309-2319.

79. Milsom CC, Yu JL, Mackman N, Micallef J, Anderson GM, Guha A, Rak JW: Tissue factor regulation by epidermal growth factor receptor and epithelial-to-mesenchymal transitions: effect on tumor initiation and angiogenesis. Cancer Res 2008, 68:10068-10076.

80. Sade-Feldman M, Kanterman J, Ish-Shalom E, Elnekave M, Horwitz E, Baniyash M: Tumor necrosis factor-alpha blocks differentiation and enhances suppressive activity of immature myeloid cells during chronic inflammation. Immunity 2013, 38:541-554.

81. Krisinger MJ, Goebeler V, Lu Z, Meixner SC, Myles T, Pryzdial EL, Conway EM: Thrombin generates previously unidentified C5 products that support the terminal complement activation pathway. Blood 2012, 120:1717-1725.

82. Markiewski MM, DeAngelis RA, Benencia F, Ricklin-Lichtsteiner SK, Koutoulaki A, Gerard C, Coukos G, Lambris JD: Modulation of the antitumor immune response by complement. Nat Immunol 2008, 9:1225-1235.

83. Ferjancic S, Gil-Bernabe AM, Hill SA, Allen PD, Richardson P, Sparey T, Savory E, McGuffog J, Muschel RJ: VCAM-1 and VAP-1 recruit myeloid cells that promote pulmonary metastasis in mice. Blood 2013, 121:3289-3297.

84. Falanga A, Russo L: Epidemiology, risk and outcomes of venous thromboembolism in cancer. Hamostaseologie 2012, 32:115-125.

85. Lazo-Langner A, Goss GD, Spaans JN, Rodger MA: The effect of low-molecular-weight heparin on cancer survival: a systematic review and meta-analysis of randomized trials. J Thromb Haemost 2007, 5:729-737.

86. Klerk CP, Smorenburg SM, Otten HM, Lensing AW, Prins MH, Piovella F Prandoni P, Bos MM, Richel DJ, van Tienhoven G, Buller HR: The effect of low molecular weight heparin on survival in patients with advanced malignancy. J Clin Oncol 2005, 23:2130-2135.

87. Hull RD, Townshend G: Long-term treatment of deep-vein thrombosis with low-molecular-weight heparin: an update of the evidence. Thromb Haemost 2013, 110:14-22.

88. Morel O, Jesel L, Freyssinet JM, Toti F: Cellular mechanisms underlying the formation of circulating microparticles. Arterioscler Thromb Vasc Biol 2011, 31:15-26.

89. Hron $G$, Kollars M, Weber H, Sagaster V, Quehenberger P, Eichinger S, Kyrle PA, Weltermann A: Tissue factor-positive microparticles: cellular origin and association with coagulation activation in patients with colorectal cancer. Thromb Haemost 2007, 97:119-123.

90. Del Conde I, Bharwani LD, Dietzen DJ, Pendurthi U, Thiagarajan P, Lopez JA: Microvesicle-associated tissue factor and Trousseau's syndrome. J Thromb Haemost 2007, 5:70-74.

91. Tesselaar ME, Romijn FP, Van Der Linden IK, Prins FA, Bertina RM, Osanto S: Microparticle-associated tissue factor activity: a link between cancer and thrombosis? J Thromb Haemost 2007, 5:520-527.

92. Tesselaar ME, Romijn FP, van der Linden IK, Bertina RM, Osanto S: Microparticle-associated tissue factor activity in cancer patients with and without thrombosis. J Thromb Haemost 2009, 7:1421-1423.

93. Zwicker Jl, Liebman HA, Neuberg D, Lacroix R, Bauer KA, Furie BC, Furie B: Tumor-derived tissue factor-bearing microparticles are associated with venous thromboembolic events in malignancy. Clin Cancer Res 2009, 15:6830-6840.

\section{doi:10.1186/s13045-014-0054-8}

Cite this article as: Han et al.: Tissue factor in tumor microenvironment: a systematic review. Journal of Hematology \& Oncology 2014 7:54.

\section{Submit your next manuscript to BioMed Central and take full advantage of:}

- Convenient online submission

- Thorough peer review

- No space constraints or color figure charges

- Immediate publication on acceptance

- Inclusion in PubMed, CAS, Scopus and Google Scholar

- Research which is freely available for redistribution 